\title{
educação

\section{Perceção dos professores sobre a avaliação do desempenho docente}

\author{
Maria Piedade Alves ${ }^{1} \&$ Pedro Cunha ${ }^{\mathrm{II}}$ \\ Universidade Fernando Pessoa, Portugal
}

Abílio Afonso Lourenço III

Agrupamento de Escolas Alexandre Herculano, Portugal

Ana Paula Monteiro ${ }^{\mathrm{IV}}$

Universidade de Trás-os-Montes e Alto Douro, Portugal

Existe um consenso de que o desenvolvimento de um país depende da qualidade da sua educação. Assim, a Avaliação de Desempenho Docente (ADD) surgiu porque o Ministério da Tutela acredita que esta pode contribuir para a qualidade da educação, bem como para a valorização e o desenvolvimento pessoal e profissional dos professores. Todavia, o tema é complexo, tendo dado origem a intensa contestação docente e sindical em Portugal. Este estudo pretendeu conhecer como os professores percecionam a avaliação de desempenho. Para tal, procedeu-se a uma investigação quantitativa numa amostra constituída por 240 professores a exercerem funções em Portugal Continental, aos quais administrámos um inquérito por questionário. Os dados recolhidos foram tratados e analisados utilizando a técnica de modelação de equações estruturais. As principais conclusões apontam, quanto ao género, habilitações académicas e tempo de serviço, para a existência de algumas associações com a perceção que os professores possuem sobre a adequação da avaliação de desempenho. Os resultados revelam ainda que os professores que apresentam um melhor entendimento sobre a avaliação de desempenho consideram cumprir mais os objetivos e manifestam ter melhor prática científica e pedagógica, sendo também aqueles que manifestam menor perceção da adequação do processo de avaliação docente.

Palavras-chave: Avaliação; Desempenho; Professores

\section{IN T ROD U Ç Ã O}

A avaliação de desempenho docente (ADD) consiste na observação e apreciação sistemática do comportamento profissional e das capacidades técnicas de um trabalhador ou colaborador docente no exercício da sua atividade, bem como dos resultados e progressos obtidos (Alves, 2016; Beatty, 2016; Braz, 2013; Bullis, 2014; Machado \& Portugal, 2014; Pires, 2014).

Os estudos comparativos acerca de políticas nacionais que promovam o sucesso escolar 
devem levar os responsáveis da educação a avaliar mais (alunos, professores e diretores) e a definir políticas em função de dados objetivos (Raymond \& Negassi, 2015). A avaliação de desempenho deve igualmente ser um processo contínuo de apreciação acerca dos conhecimentos, do trabalho, da forma de relacionamento e do saber-estar dos professores (Raymond \& Negassi, 2015).

Assim, a ADD é considerada um instrumento importante no sistema educativo, procurando cumprir três objetivos principais (Graça, Duarte, Lagartixa, \& Tching, 2011): desenvolvimento profissional (faculta à escola informação que lhe permite promover atividades que conduzam ao desenvolvimento profissional do seu corpo docente, contribuindo para a melhoria da qualidade da escola); responsabilização (reconhece as boas práticas e as situações em que o desempenho docente se encontra aquém das suas potencialidades, permitindo à escola identificar necessidades de formação e desenvolver processos que levem à melhoria do desempenho dos professores); e motivação (constitui um fator de motivação para os professores atestarem o reconhecimento do seu desempenho).

Como estratégia política, a avaliação de desempenho docente (de todos os graus de ensino), tem sido objeto de muitas reflexões. Não constitui uma tarefa fácil, pois depara-se com resistências por parte dos envolvidos no processo, suscitando frequentemente medos e dúvidas quanto ao processo em si e às consequências do mesmo.

Uma das questões que importa analisar e para a qual encontrar soluções relaciona-se com os diferentes pontos de vista dos interessados (Fernandes, 2008). Os professores focalizam-se na defesa dos postos de trabalho ou na progressão na carreira, bem como na sua dignidade pessoal e profissional, enquanto os pais, os encarregados de educação e a administração das escolas estão mais interessados num sistema de avaliação que relacione o ensino com os resultados dos alunos, ou seja, o desempenho dos professores com a sua eficácia (Fernandes, 2008).

\section{AVAliação De DeSEMPENHO DOCENTE NO CONTEXTO PORTUGUÉS}

Em Portugal, antes de 1974, a ADD era da responsabilidade dos inspetores e/ou dos reitores. A prestação dos professores era classificada numa escala que contemplava as categorias de Medíocre, Suficiente, Bom e Muito Bom. De 1974 a 1986, a avaliação de desempenho docente foi praticamente inexistente. Em 1986 é publicada a Lei de Bases do Sistema Educativo (Lei n. ${ }^{\circ} 46 / 86$, de 14 de outubro) e a questão da avaliação docente é novamente abordada. Em 1990, com o Decreto-Lei n. ${ }^{\circ} 139-A / 90$, de 28 de abril, é publicado o Estatuto da Carreira Docente e, pela primeira vez, a progressão na carreira passa a ficar dependente da avaliação.

Pretendendo apenas sinalizar alguns dos normativos legais sobre a $\mathrm{ADD}$, refira-se que bastante legislação sobre esta temática foi publicada ao longo dos anos, mas a grande alteração ao sistema de ADD foi introduzida pelo Decreto-Lei n. ${ }^{\circ}$ 15/2007, de 19 de janeiro, que altera o Estatuto da Carreira Docente. Este decreto-lei implica uma reforma estrutural e impõe um olhar crítico-reflexivo sobre a avaliação. Apresenta como objetivos principais o aperfeiçoamento das práticas, com vista à melhoria dos resultados escolares e à qualidade das aprendizagens, e garantir a diferenciação dos professores pelo mérito através do estabelecimento de quotas para as classificações de Excelente e de Muito Bom. Nesta avaliação deveria ser considerada a totalidade das atividades desenvolvidas pelo docente: componente pedagógica, serviço distribuído e participação/ envolvimento com a "vida" da escola e da própria comunidade. Com este regime de avaliação pretendia-se uma melhoria das aprendizagens e 
que tal tivesse reflexos nos resultados escolares dos alunos.

O Decreto Regulamentar n. ${ }^{\circ}$ 2/2008, de 10 de janeiro, trouxe mudanças significativas. Regulamentou o Estatuto da Carreira Docente no que se refere, sobretudo, ao sistema de Avaliação de Desempenho do Pessoal Docente, estabelecendo também as normas relativas ao regime transitório para aplicação em 2007/2008. Este decreto pretende criar os mecanismos de aplicação do novo sistema de avaliação de desempenho docente, sobretudo dos docentes integrados na carreira, concretizando a matéria relativa ao planeamento das atividades de avaliação, à fixação dos objetivos individuais, bem como as matérias relativas ao processo (calendarização, explicitação dos parâmetros avaliativos e sistema e classificação).

Mais recentemente, o Decreto Regulamentar $n^{\circ} 26 / 2012$, de 21 de fevereiro, promove ciclos de avaliação mais longos, coincidindo com a duração dos escalões da carreira, fomenta a dimensão formativa da avaliação e recorre a avaliadores externos para a observação de aulas no período probatório, $2^{\circ}$ e $4^{\circ}$ escalões $^{1}$ e em caso de obtenção da menção de Excelente. Nos restantes escalões, a avaliação tem uma natureza interna e efetua-se com recurso a um relatório de autoavaliação realizado pelo docente; tem como menção os parâmetros aprovados pelo Conselho Pedagógico, constituindo-se neste órgão a secção de avaliação do desempenho docente. A avaliação do desempenho docente passa a recair sobre três grandes dimensões: a científicopedagógica, que assume a centralidade no exercício profissional; a participação na vida da escola e a relação com a comunidade educativa; e a formação contínua e o desenvolvimento profissional.

A implementação de um sistema de avaliação docente no sentido de monitorizar a qualidade de ensino nas salas de aula pressupõe enfrentar alguns desafios e, simultaneamente, proporciona algumas oportunidades para todos os atores que participam no processo (Rodrigues, 2012). Rodrigues (2012) refere que um dos principais reptos a ultrapassar é de cariz cultural e corresponde a uma lógica de avaliação associada à classificação, seriação e seleção, e não encarada como um processo formativo com o objetivo de potenciar o desenvolvimento e as aprendizagens. Para Fernandes (2008), os fins a que se destina a avaliação devem ser considerados ao escolher os procedimentos de recolha de dados, assim como o tipo de interação que o avaliador estabelece com o avaliado, ou seja, deve ser definido o design que o sistema de avaliação pretende assumir. Alguns elementos cruciais para superar obstáculos que surgem na implementação de um sistema de ADD são identificados por Isoré (2010): participação na conceção do processo; conhecimento dos critérios de obtenção de uma boa avaliação; viabilidade e confiabilidade do sistema; objetividade dos resultados e inexistência de uma avaliação exclusiva do avaliador (o qual deve ser especialista do conteúdo avaliado e de uma escola diferente do avaliado).

A avaliação dos professores pode ser uma mera rotina burocrática e administrativa, consumidora de tempo, esforço e dinheiro e com pouca ou mesmo nenhuma utilidade para influenciar positivamente o desempenho, a competência e a eficácia dos professores e o que acontece nas escolas (Fernandes, 2008). Mas também pode ser, pelo contrário, um poderoso processo ao serviço da melhoria da qualidade pedagógica e da qualidade de ensino dos professores, gerando ambientes propícios à inovação, ao desenvolvimento profissional e, consequentemente, ao incremento

\footnotetext{
${ }^{1}$ Em Portugal, o Estatuto da Carreira Docente é organizado em 10 escalões. Os escalões têm a duração de quatro ou dois anos de tempo de serviço contabilizado para efeitos de progressão na carreira.
} 
das aprendizagens dos alunos. Os sistemas de avaliação de professores devem abranger três componentes (Danielson, 2001): uma definição clara de uma boa prática pedagógica (o quê); métodos justos e confiáveis de uma boa prática pedagógica (como); e avaliadores com experiência capazes de fazer uma avaliação objetiva e coerente. A avaliação docente deve ter por base um processo de desenvolvimento pessoal e profissional com potencial para ter impacto positivo nas aprendizagens dos alunos (Ventura, 2012). Assim, importa avaliar os professores através de um modelo que nos faculte informação credível sobre a forma como desempenham as suas funções. Para que tal aconteça, é indispensável que promova a aprendizagem profissional de todos os envolvidos, através de um ambiente colegial e colaborativo (Ventura, 2012).

No contexto nacional, reconhecida a centralidade da avaliação nos discursos e nas práticas (Morgado, 2014), a ADD tem sido alvo de várias investigações, sobretudo de tipo qualitativo, sobre perceções, representações e perspetivas quanto à mesma por parte dos docentes (cf. Coelho, 2013; Costa \& Fialho, 2012; Ferreira \& Oliveira, 2015; Serrano, 2015). Globalmente, os estudos citados apontam que os professores consideram a ADD como uma necessidade para o desenvolvimento profissional, demonstrando uma atitude de abertura e de aprendizagem face à implementação da mesma. No entanto, as investigações sugerem igualmente que os docentes têm a perceção de que o atual modelo de ADD não contribui plenamente para atingir os objetivos para os quais a avaliação deveria contribuir. Com base no exposto, justifica-se a realização de uma investigação de caráter quantitativo e dedicada a analisar a relação entre um conjunto de variáveis, ainda relativamente pouco estudadas, e as perceções sobre a avaliação do desempenho docente em Portugal.

\section{Avaliação de Desempenho DOCENTE: BREVE PANORÂMICA IN TERNACIONAL}

A avaliação dos professores está presente em muitos países, ainda que de diferentes formas. $\mathrm{Na}$ Europa Ocidental, há países em que a avaliação não se faz de forma externa e generalizada: Áustria, Bélgica, Chipre, Dinamarca, Espanha, Finlândia, Irlanda, Itália, Islândia, Liechtenstein, Luxemburgo, Noruega, Países Baixos, Reino Unido (Escócia) e Suécia (Murillo, 2007). Por outro lado, há países onde a avaliação do desempenho dos professores tem esse carácter externo e sistemático, como a Alemanha, Eslovénia, Estónia, França, Grécia, Lituânia, Malta Polónia, Portugal, Roménia e Reino Unido. No continente americano, integram esta lista Argentina, Bolívia, Chile, Colômbia, Costa Rica, El Salvador, Honduras, México, Peru, Porto Rico, República Dominicana, Uruguai, Venezuela e, nos Estados Unidos, a Califórnia e a Carolina do Norte (Murillo, 2007).

Os sistemas de avaliação do desempenho docente apresentam variações que os distinguem. $\mathrm{Na}$ Califórnia e na Carolina do Norte (EUA), os critérios são o progresso dos alunos, as técnicas e as estratégias pedagógicas utilizadas, o grau de adesão aos objetivos curriculares e a criação de um clima de aula adequado à aprendizagem (Murillo, 2007).

No Reino Unido, a política do desempenho inclui um acordo dos objetivos com cada docente, um calendário anual no âmbito do plano da escola e documentação normalizada para todos os professores desta. A implementação da avaliação desenvolve-se em três fases: planeamento, recolha de informação e retorno da informação sobre o desempenho (Murillo, 2007). Nas Escolas Secundárias de grande dimensão, o diretor avalia diretamente o pessoal docente que lhe está mais próximo, que, depois, avalia os professores em geral. O sistema do gestor 
de performance, que teve início em 1990, leva a que o regime remuneratório esteja diretamente ligado à avaliação (Lima, 2008).

Na Dinamarca, Finlândia, Noruega, Suécia e Países Baixos, a ADD é da responsabilidade da escola, tendo esta a possibilidade de implementar processos avaliativos que podem ter repercussões no vencimento dos professores (Murillo, 2007).

Na Islândia, desde 1985, cada escola implementa o seu próprio sistema e determina a forma como os professores realizam a autoavaliação (Lima, 2008).

Em Espanha, as finalidades da avaliação residem em melhorar a qualidade e a equidade, orientar políticas educativas, aumentar a transparência e a eficácia do sistema educativo e verificar o grau de cumprimento dos objetivos (Àlvarez, 2007), sendo que a ADD por parte de diretores de estabelecimentos de ensino só acontece em algumas comunidades autónomas.

Em França, todos os funcionários públicos estão sujeitos à avaliação conforme o estipulado no art. ${ }^{\circ} 2 .^{\circ}$ do Décret n. ${ }^{\circ} 2002-682$, de 29 de abril. A avaliação dos professores é realizada de forma diferente, conforme se trata de professores do primeiro grau ( $1^{\circ}$ ciclo e $5^{\circ}$ ano) ou professores do segundo grau ( $6^{\circ}$ ano, $3^{\circ}$ ciclo e Ensino Secundário). Os primeiros são avaliados através de uma avaliação pedagógica efetuada por um inspetor académico, nomeado pela Inspeção da Educação Nacional, que verifica o cumprimento dos programas e dos horários e a qualidade pedagógica (pela observação de uma aula). Os segundos estão sujeitos a uma dupla avaliação administrativa e pedagógica (Hadji, 2010). É de salientar que a França, o Luxemburgo e a Turquia são os países onde as inspeções representam o procedimento mais importante para a avaliação dos professores (Comissão Europeia/EACEA/ Eurydice, 2013).

$\mathrm{Na}$ Áustria, apresentam-se quatro áreas de trabalho docente: a qualidade do ensino, o desempenho do professor como facilitador/ educador, o desempenho do professor como elemento da equipa e o contributo do professor para a qualidade pedagógica da escola (Schmid, 2007).

Noutros países, como é o caso da Argentina, Chile e Roménia, os critérios utilizados são os próprios escalões da carreira, tendo os resultados da avaliação, em cada um dos escalões, um papel muito importante (Murillo, 2007; Urriola, 2013). $\mathrm{Na}$ Bolívia, os professores têm que realizar um exame teórico-prático de aptidão profissional. Os professores que não superarem essa prova têm uma segunda oportunidade no ano seguinte. Se não forem aprovados, serão suspensos da função docente, sem trabalho e sem salário, até que a superem, numa terceira oportunidade, que é a última. Se voltarem a reprovar, ficarão afastados, definitivamente, dos serviços de ensino público (Murillo, 2007). No Peru são considerados quatro elementos: a eficiência no serviço, o apoio e a pontualidade, a participação no trabalho comunitário e a promoção social. Na Eslovénia, os critérios de avaliação são os conhecimentos, as capacidades, as competências multidisciplinares, a autonomia, a fiabilidade, a criatividade e o desempenho profissional, o trabalho colaborativo com os colegas e as relações com os pais e encarregados de educação (Murillo, 2007).

Os exemplos apresentados mostram que existe uma enorme diversidade de critérios e procedimentos na $\mathrm{ADD}$, não existindo uma visão unânime e, por conseguinte, um modelo comum a todos os países. Contudo, há três aspetos que podemos considerar transversais a todos eles: proporcionar o crescimento profissional dos professores, contribuir para a melhoria da prática pedagógica e promover o sucesso escolar dos alunos.

Nesse sentido, é de destacar que na sessão de 11.11.2014 do Parlamento Europeu surgiu uma proposta de resolução, apresentada nos termos do art. $^{\circ} 133^{\circ}$, alínea I, do Regimento sobre a 
criação de um sistema europeu único de acesso à carreira docente, de formação contínua e de avaliação de desempenho. Tal leva-nos a concluir que a ADD é uma temática de debate nacional e internacional, fazendo parte das agendas políticas dos diversos países.

\section{MÉ T ODO}

\subsection{OBJETIVOS DO ESTUDO}

Este estudo teve como objetivo principal analisar a perceção dos professores face à avaliação do desempenho docente e a sua relação com um conjunto de variáveis (género, habilitações académicas, tempo de serviço, avaliação, cumprimento de objetivos e prática científica e pedagógica). Verifica-se, igualmente, a inexistência de escalas, validadas para o contexto português, que possam aferir dados relativamente aos constructos em análise. Assim, pretende-se com este estudo saber quais as variáveis (pessoais e profissionais), e respetivas interações, que podem contribuir para o entendimento sobre os processos que estão na base da avaliação do desempenho docente, assim como a sua importância para a praxis docente. Consideramos o estudo dotado de alguma originalidade, sobretudo através da metodologia utilizada, que permite relacionar variáveis observáveis com variáveis inferidas e não observáveis.

\subsection{Amostra}

A amostra deste estudo foi obtida por conveniência. Participaram neste estudo 240 professores do ensino público de escolas dos distritos de Aveiro, Bragança, Coimbra, Guarda, Leiria, Porto, Viana do Castelo, Vila Real e Viseu. A amostra era constituída por 77 professores do género masculino $(32,1 \%)$ e 163 do género feminino $(67,9 \%)$, de diferentes grupos de docência - Português e Estudos Sociais/História, Português e Francês, Matemática e Ciências da Natureza, Educação Visual e Tecnológica, Electrotecnia, Português, Inglês, Filosofia, Física e Química, entre outros. Metade dos participantes (120) tinha idades compreendidas entre os $41 \mathrm{e}$ os 50 anos. Relativamente ao tempo de serviço letivo, 118 (49,2\%) possuíam entre 21 e 30 anos. No que concerne à formação académica, 168 (70\%) possuíam uma licenciatura, $59(24,6 \%)$ detinham um mestrado e 7 (2,9\%) detinham um doutoramento.

\subsection{INSTRUMENTO DE RECOLHA DE DADOS}

Devido à inexistência de um instrumento que pudesse estimar, de uma forma holística, a avaliação do desempenho docente no contexto português, foi opção construir de raiz um questionário que comportasse, de uma forma organizada e lógica, as questões que se pretendia mensurar.

Este instrumento, de cariz exploratório, foi administrado em forma de pré-teste a 15 professores de duas escolas de Viseu, com o objetivo de o aperfeiçoar quanto à compreensão da estrutura e linguagem utilizada no mesmo.

O questionário era constituído por: i) uma ficha de dados pessoais e profissionais dos professores (FDPP), onde se recolhiam dados relativos ao género, idade, tempo de serviço e formação académica; ii) três escalas dimensionadas para quantificar as respostas relacionadas com a "avaliação", "cumprimento de objetivos" e "prática científica e pedagógica" (cf. Tabela 1); iii) um conjunto de questões associadas ao "processo de avaliação"; e iv) um grupo de itens relativos ao "avaliador", nomeadamente acerca do comportamento, qualidade no trabalho, iniciativa, eficiência e responsabilidade. Contudo, este último grupo de questões não foi considerado no modelo proposto. 
TA B ELA 1 - Escalas e respetivos itens do questionário

\begin{tabular}{|c|c|}
\hline Escala & Itens \\
\hline Avaliação & $\begin{array}{l}\text { 1. O RAA permite que os docentes façam uma reflexão crítica. } \\
\text { 2. O RAA é uma fonte válida de avaliação de desempenho docente. } \\
\text { 3. O RAA constitui uma oportunidade de auto crítica do trabalho relativamente às práticas } \\
\text { implementadas. } \\
\text { 4. A função do RAA é permitir que os docentes identifiquem oportunidades de desenvolvimento } \\
\text { profissional. } \\
\text { 5. A função do RAA é envolver os avaliados no processo de avaliação. } \\
\text { 6. O RAA é um instrumento de controlo da atividade docente. } \\
\text { 7. No RAA os docentes inflacionam positivamente as apreciações que fazem de si próprios. } \\
\text { 8. No RAA os docentes identificam os seus pontos fortes. } \\
\text { 9. No RAA os docentes identificam os seus pontos fracos. } \\
\text { 10. No RAA os docentes referem o que consideram "politicamente correto". } \\
\text { 11. No RAA os docentes recorrem a "frases feitas" que pouco revelam sobre os seus } \\
\text { desempenhos. } \\
\text { 12. No RAA os docentes fazem uma réplica de autoavaliações anteriores. } \\
\text { 13. O RAA não serve para nada. }\end{array}$ \\
\hline $\begin{array}{l}\text { Cumprimento de } \\
\text { objetivos }\end{array}$ & $\begin{array}{l}\text { 1. Cumpre o programa da(s) disciplina(s) lecionada(s). } \\
\text { 2. É assíduo(a). } \\
\text { 3. Conhece o Projeto Educativo da Escola, Regulamento Interno e Plano Anual de Atividades } \\
\text { da escola/agrupamento. } \\
\text { 4. Mantém o comportamento respeitoso e profissional no trato com a direção, encarregados de } \\
\text { educação, assistentes operacionais/administrativos e alunos. } \\
\text { 5. Participa de forma proativa nas atividades desenvolvidas na escola/agrupamento. } \\
\text { 6. Apresenta soluções para melhoria do trabalho na escola/agrupamento. } \\
\text { 7. Frequenta ações de formação, contribuindo para melhores práticas na escola/agrupamento } \\
\text { 8. Executa trabalhos com qualidade de acordo com os parâmetros estabelecidos. } \\
\text { 9. Executa os trabalhos dentro do prazo determinado. } \\
\text { 10. Responde com facilidade a pedidos inesperados no trabalho. } \\
\text { 11. Cumpre prazos e compromissos assumidos. } \\
\text { 12. Envolve-se com objetivos e metas na escola/agrupamento. } \\
\text { 13. Possui atitude, ética e profissionalismo no desempenho das suas atribuições. } \\
\text { 14. Preocupa-se com a imagem e credibilidade da escola/agrupamento. }\end{array}$ \\
\hline
\end{tabular}

1. Planifica com correção científico-pedagógica, integrando de forma coerente e inovadora propostas de atividades, meios, recursos e tipos de avaliação das aprendizagens, em função da(s) especificidade(s) de cada uma das turmas que lhe são atribuídas.

2. Avalia sistematicamente as aprendizagens dos alunos com rigor, implementando práticas de avaliação diagnóstica, formativa e sumativa, potencializando a interiorização, pelos alunos, das suas dificuldades e progressos.

Prática científica e 3. Apresenta sugestões com vista à melhoria da qualidade da escola, no sentido de promover $o$ pedagógica trabalho colaborativo, de forma sistemática, em prol da consecução dos objetivos e metas dos referentes internos da escola.

4. Promove de forma ativa a reflexão alargada, no âmbito das estruturas de coordenação educativa em que participa, sobre desenvolvimento de ações/intervenções inovadoras, tendo em vista a eficácia e eficiência dos serviços prestados pela escola.

5. Participa de forma sistemática em processos de aquisição e atualização de conhecimento profissional, que contribuem para a melhoria da sua prática docente.

RAA: Relatório de Autoavaliação 


\subsection{PROCEDIMENTOS}

Em primeiro lugar, solicitou-se a respetiva autorização à Direção-Geral da Educação². De acordo com as escolas e respetivas rotinas, o procedimento de recolha de dados ocorreu de forma diferenciada. Na maior parte das escolas, os questionários foram deixados no órgão de gestão e recolhidos posteriormente. Noutros casos, foi possível aplicar o questionário com a presença do investigador, tendo sido solicitado aos professores que respondessem com o máximo de sinceridade, tentando não esquecer nenhum item. Os professores foram bastante recetivos, tendo sido garantidos os procedimentos éticos e deontológicos convencionais, designadamente a confidencialidade das respostas e a voluntariedade na participação.

\subsection{TÉCNICAS DE ANÁlise de Dados}

Para a validação da análise preditiva da relação das variáveis em estudo, foi utilizado um modelo de Structural Equation Modelling (SEM) (Lowe, Winzar, \& Ward, 2007; Ullman \& Bentler, 2004) tendo como suporte o programa informático SPSS/AMOS 21. A técnica SEM possibilita avaliar as relações causais entre variáveis inferidas (não diretamente observadas) através de um conjunto de variáveis observadas que servem de marcadores de cada variável inferida ou latente. Esta técnica tem vantagens sobre outras, tais como: i) salienta que a variância não é estável ao longo do tempo; ii) possibilita calcular os erros das medidas (variáveis observadas); e iii) permite calcular, rapidamente, a significância estatística de cada efeito causal e o ajustamento global do modelo hipotético (Byrne, 2001). Se o ajustamento global do modelo testado for apropriado, aprovam-se as relações ou efeitos apresentados pelo modelo.

Esta análise estatística permite-nos verificar se há valores em falta e a presença de outliers, de linearidades e de normalidade, pois esta metodologia requer que as variáveis em estudo sigam uma distribuição normal. Devido ao facto de a máxima verossimilhança (ML) poder produzir uma distorção quando a suposição de normalidade é violada (West, Finch, \& Curran, 1995), foi examinada a distribuição das variáveis (assimetrias e curtoses). Considerando o critério de Finney e DiStefano (2006), em que 2 e 7 são identificados como valores máximos admissíveis para assimetria e curtose, todas as variáveis atendem aos critérios (cf. Tabela 2 na secção seguinte). Assim, o modelo foi ajustado usando a ML.

Uma vez delineado o modelo, é testada a veracidade de todas as relações definidas entre as variáveis, de forma total, naquilo que se denomina "ajustamento global do modelo", ou seja, é verificada a adequação do modelo à matriz dos dados. Este ajustamento global é inferido com base num conjunto de índices, designados de índices de ajustamento global do modelo, nomeadamente: $\chi^{2} ; \chi^{2} / \mathrm{gl}$; GFI; AGFI; CFI; TLI e RMSEA (Byrne, 2001; Hair, Anderson, Tatham, \& Black, 2005; Schreiber, Nora, Stage, Barlow, \& King, 2006).

Relativamente aos índices de ajustamento GFI (Goodness-of-Fit Index) (Jöreskog \& Sörbom, 1983), AGFI (Adjusted Goodness-of-Fit Index) (Hu \& Bentler, 1995), CFI (Comparative Fit Index) (Bentler, 1990) e TLI (Tucker-Lewis Index) (Bollen, 1989), os valores iguais ou superiores a .90 nestes índices são, normalmente, considerados indicadores de ajustamento do modelo. No que se refere ao RMSEA (Root Mean Square Error of Approximation), introduzido por Browne e Cudeck (1993), é um indicador que

\footnotetext{
${ }^{2}$ Monitorização de Inquéritos em Meio Escolar: inquérito 0479200001
} 
aponta o erro de aproximação à população e um dos mais sensíveis no ajustamento do modelo. Esta diferença é indicada em graus de liberdade, o que torna este índice sensível ao número de parâmetros estimados, dando complexidade ao modelo. Segundo Byrne (2001), os valores, que variam entre .08 e .05 , denunciam um ajuste razoável e quando se apresentam inferiores a .05 indicam um bom ajuste.

Para se identificar a qualidade do ajustamento do modelo, que consta da avaliação de um conjunto de possíveis incoerências das estimativas dos diversos parâmetros (Byrne, 2001), serão apresentados, somente, os valores estimados (estandardizados e não estandardizados), a estimativa da variância das variáveis exógenas e as correlações múltiplas quadradas (Squared Multiple Correlations).

\section{Apresentação dos resultados}

Devido ao formato Likert dos itens, o cálculo da consistência interna, que procura analisar em que medida os itens que compõem o teste se apresentam como um todo homogéneo, foi realizado a partir da determinação do índice Alpha de Cronbach. Desta forma, a escala que se denominou "Avaliação" pretendia dar a conhecer os constrangimentos que esta prática tem junto dos professores, através do relatório de autoavaliação (RAA). Era composta por 13 itens e as respostas dos professores foram avaliadas numa escala tipo Likert de cinco classificadores - designadamente: 1 (nunca); 2 (raramente); 3 (às vezes); 4 (frequentemente); e 5 (sempre) -, apresentando um valor de .71 para o Alpha de Cronbach total da escala.

Para medir o "Cumprimento de objetivos" foi utilizada uma escala com 14 itens que tinha a finalidade de avaliar alguns aspetos relacionados com o cumprimento de programas da disciplina, prazos, assiduidade, relacionamento com a comunidade educativa e questões éticas e deontológicas. As respostas dos inquiridos foram avaliadas na mesma escala tipo Likert de cinco classificadores, tendo-se encontrado um valor de .87 para o Alpha de Cronbach total da escala.

Relativamente à "Prática científica e pedagógica", foi estruturada uma escala com cinco itens cujo objetivo era estimar o comportamento profissional e as capacidades técnicas do professor no exercício da sua atividade no contexto educativo. O conjunto destes itens exibe um Alpha de Cronbach de .83 e as respostas foram avaliadas, igualmente, segundo uma escala tipo Likert com cinco classificadores.

No que concerne à questão onde era considerado o "Processo de avaliação", esta continha duas alternativas de resposta - adequado e inadequado -, possibilitando ao respondente, de uma forma opcional, dar uma explicação para a sua escolha. Tinha como objetivo auscultar os professores acerca da adequabilidade deste processo de avaliação, em 2016. De realçar que os coeficientes de Alpha de Cronbach das três escalas consideradas se situaram entre os valores .71 e .87 , o que aponta para um bom índice de fidelidade das mesmas. Atendendo aos valores de fidelidade encontrados para as diferentes escalas consideradas, podemos referir que os mesmos estão no nível recomendado por Streiner (2003), dando-nos garantias da consistência interna do instrumento.

Após a recolha dos dados relativos às dimensões em estudo, fez-se a sua aplicação no modelo hipotetizado (Figura 1) com a amostra de 240 professores. Este modelo avalia em que medida as variáveis exógenas (ou observáveis) - género, habilitações académicas e tempo de serviço dos professores - podem ter influência nas variáveis endógenas (ou latentes) - avaliação, cumprimento de objetivos e prática científica e pedagógica -, assim como na perceção da adequação (ou não) do processo de avaliação docente.

Considera-se expectável que os professores, independentemente do seu género, habilitação 
científica e tempo de serviço, tenham uma opinião formada sobre a importância da avaliação do seu desempenho como docentes, sobre a necessidade de cumprir os objetivos propostos, assim como a perceção da sua autoeficácia científica e pedagógica. Consequentemente, este autoconhecimento consciente ajudará a ter uma perceção mais clara da adequação (ou não) do processo de avaliação docente.

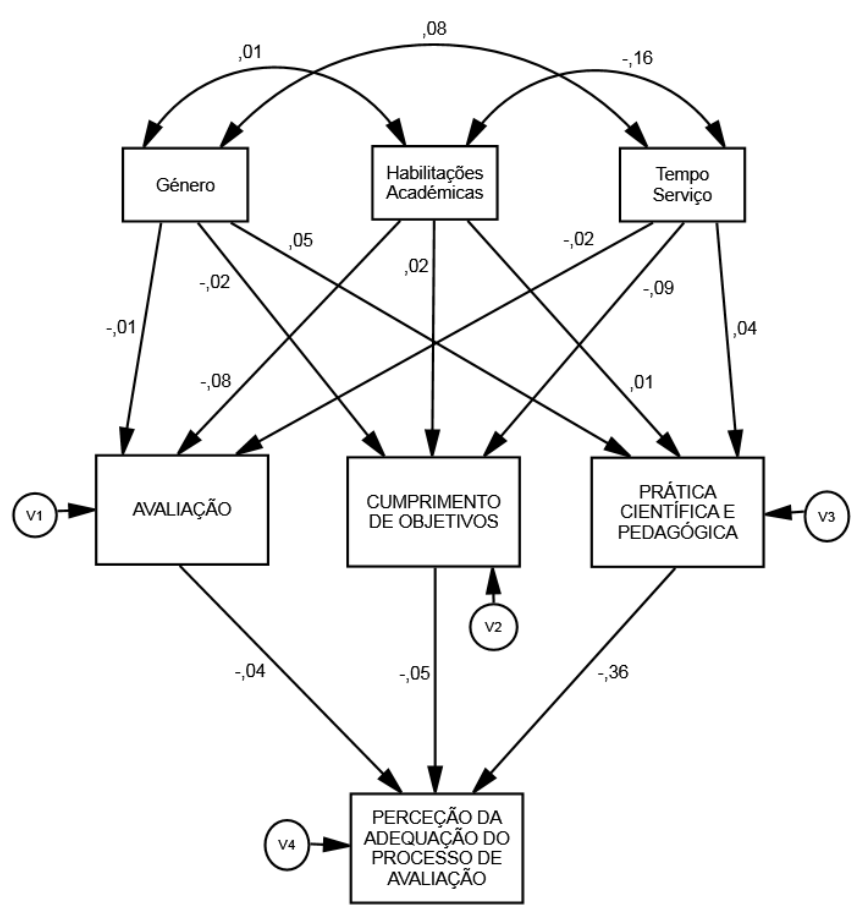

FI G U RA 1 - Especificação pictórica do modelo de relações causais hipotetizadas

$\mathrm{Na}$ Tabela 2, poder-se-á observar os dados descritos (média, desvio-padrão, assimetria, curtose, mínimos e máximos) correspondentes às variáveis incluídas no modelo de estrutura covariante na amostra considerada.

TA B ELA 2 - Estatística descritiva (média, desvio-padrão, assimetria, curtose, mínimos e máximos) correspondente às variáveis endógenas incluídas no modelo.

\begin{tabular}{lccccccc}
\hline & \multicolumn{7}{c}{ Amostra N=240 } \\
\cline { 2 - 7 } & Min. & Máx. & M & DP & Assimetria & Curtose \\
\hline Avaliação & 28 & 65 & 43,45 & 6,021 & .288 & 1.414 \\
\hline Cumprimento de objetivos & 20 & 70 & 60,05 & 7,725 & -1.921 & 5.766 & -1.393 \\
\hline Prática científica e pedagógica & 5 & 25 & 16,33 & 6,671 & -.298 & -1.162 & -.655 \\
\hline Perc. Adeq. Proc. Avaliação & 1 & 2 & 1,75 & .434 & & -62 \\
\hline
\end{tabular}

No que concerne à normalidade das variáveis incluídas no modelo, podemos constatar, a partir da Tabela 2, que os dados apresentados estão de acordo com o estabelecido por Finney e DiStefano (2006), para quem 2 e 7, respetivamente, são os valores máximos permitidos para assimetria e curtose. 
4.1 ANÁlise do MODELO DE EQUAÇÕES ESTRUTURA IS

A Figura 1 apresenta o modelo hipotetizado para a amostra considerada, assim como as relações causais possíveis entre as variáveis em estudo. Como já foi referido, a avaliação dos resultados da contrastação do modelo de equações estruturais é baseada nos critérios do nível global de ajustamento do modelo e significância dos coeficientes de regressão calculados. Osíndices debondade de ajustamento global do modelo proposto são adequados -

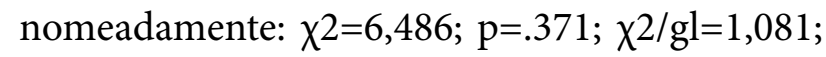
$\mathrm{GFI}=.992 ; \mathrm{AGFI}=.965 ; \mathrm{TLI}=$ 951; $\mathrm{CFI}=.986$; RMSEA=.018 -, tendo em consideração os valores-limite aceitáveis para cada um dos valores de ajustamento anteriormente descritos. É possível, assim, inferir que o modelo se ajustou de uma forma robusta, ou seja, o modelo proposto representa as relações entre as variáveis existentes na nossa matriz empírica.

Deste modo, da análise da Figura 1 e da Tabela 3 (seguidamente apresentada), pode constatarse que o sexo feminino tem uma perceção/ entendimento sobre a avaliação menos favorável do que o sexo masculino ( $\mathrm{r}=-.01 ; p=.853)$, considera cumprir menos os objetivos do que o sexo oposto $(\mathrm{r}=-.02 ; p=.738)$ e perceciona uma prática científica e pedagógica mais efetiva do que os colegas do sexo masculino $(\mathrm{r}=.05 ; p=.477)$.

TA B ELA 3 - Resultados da contrastação do modelo (valores estandardizados e não estandardizados, erro estimado e nível de significância).

\begin{tabular}{lcccc}
\hline & $\begin{array}{c}\text { Valores n/ } \\
\text { estandardizados }\end{array}$ & $\begin{array}{c}\text { Valores } \\
\text { estandardizados }\end{array}$ & $\begin{array}{c}\text { Erro de } \\
\text { estimativa }\end{array}$ & $p$ \\
\hline Sexo $\rightarrow$ Avaliação & -.155 & -.012 & .833 & .853 \\
\hline Sexo $\rightarrow$ Cumprimento de objetivos & -.356 & -.022 & 1.066 & .738 \\
\hline Sexo $\rightarrow$ Prática científica e pedagógica & .657 & .046 & .924 & .477 \\
\hline Hab. académicas $\rightarrow$ Avaliação & -.842 & -.078 & .705 & .233 \\
\hline Hab. académicas $\rightarrow$ Cumprimento de objetivos & .276 & .020 & .903 & .760 \\
\hline Hab. académicas $\rightarrow$ Prática Científica e Pedagógica & .157 & .013 & .782 & .841 \\
\hline Tempo de serviço $\rightarrow$ Avaliação & -.159 & -.022 & .480 & .740 \\
\hline Tempo de serviço $\rightarrow$ Cumprimento de objetivos & -.868 & -.092 & .614 & .158 \\
\hline Tempo de serviço $\rightarrow$ Prática científica e pedagógica & .309 & .038 & .532 & .562 \\
\hline Avaliação $\rightarrow$ Perc. Adeq. Proc. Avaliação & -.003 & -.040 & .004 & .506 \\
\hline Cumpr. objet. $\rightarrow$ Perc. Adeq. Proc. Avaliação & -.003 & -.053 & .003 & .377 \\
\hline Prática Cient. Pedag. $\rightarrow$ Perc.Adeq. Proc. Avaliação & -.024 & -.365 & .004 & $\star * *$ \\
\hline
\end{tabular}

Por sua vez, os professores que apresentam habilitações académicas superiores têm uma perceção/ entendimento sobre a avaliação menos favorável do que os restantes colegas ( $\mathrm{r}=-.08 ; p=.233)$, tendem a considerar cumprir mais os objetivos do que os restantes colegas $(\mathrm{r}=.02 ; p=.760)$, assim como a percecionar melhor prática científica e pedagógica do que os restantes professores $(\mathrm{r}=.01 ; p=.841)$. 
Tomando outra perspetiva, os professores com mais tempo de serviço têm uma perceção/ entendimento menos favorável sobre a avaliação do que os colegas com menos anos de lecionação ( $\mathrm{r}=-.02 ; p=.740)$ e tendem a considerar cumprir menos os objetivos do que os restantes colegas ( $\mathrm{r}=-.09 ; p=.158)$; contudo, indiciam percecionar uma melhor prática científica e pedagógica do que os restantes professores $(\mathrm{r}=.04 ; p=.562)$.

É observável, também, que os professores que apresentam uma maior perceção/ entendimento sobre a avaliação $(\mathrm{r}=-.04 ; p=.586)$, os que consideram cumprir mais os objetivos $(r=-.05$; $p=.377)$ e os que manifestam ter melhor prática científica e pedagógica $(r=-.36 ; p<.001)$ são aqueles que manifestam menor perceção da adequação do processo de avaliação. De realçar que esta última relação é a única que se apresenta estatisticamente significativa. Da mesma forma, a única covariância que apresenta um valor estatisticamente significativo e negativo é a existente entre as habilitações académicas e o tempo de serviço $(\mathrm{r}=-. .16 ; p<.05)$.

Relativamente às correlações múltiplas quadradas, estas indicam que a variância explicada das variáveis avaliação, cumprimento de objetivos e prática científica e pedagógica é muito baixa, ou pouco relevante, pois é de, aproximadamente, $1 \%$, isto é, $\eta 2=.006, \eta 2=.010$ e $\eta 2=.004$, respetivamente. Cada uma destas variáveis é explicada, diretamente, pelas variáveis independentes género, habilitações literárias e tempo de serviço. A variável processo de avaliação é a mais explicada no modelo, sendo o seu valor de 13,7\% (n2=.137). Esta variável é explicada, diretamente, pelas variáveis avaliação, cumprimento de objetivos e prática científica e pedagógica e, indiretamente, pelas três variáveis exógenas.

$\mathrm{Na}$ Tabela 3 é possível observar, ainda, os valores estandardizados e não estandardizados, erros estimados e nível de significância das relações hipotetizadas para a amostra em estudo.

Observando a Tabela 4, relativa às correlações de Pearson entre as variáveis incluídas no modelo, embora o ajuste tenha valores robustos (conforme os valores de ajustamento exigidos para cada índice), verificam-se, apenas, duas associações estatisticamente significativas, nomeadamente: entre as habilitações académicas e o tempo de serviço $(\mathrm{r}=-.158 ; p<.05)$, considerada muito baixa; e entre a prática científica e pedagógica e a perceção da adequação do processo de avaliação ( $\mathrm{r}=-.373 ; p<.001)$, vista como baixa.

TA B ELA 4 - Matriz de correlações das variáveis do modelo.

\begin{tabular}{|c|c|c|c|c|c|c|}
\hline & 1 & 2 & 3 & 4 & 5 & 6 \\
\hline 1. Género & - & & & & & \\
\hline 2. Habilitações académicas & .008 & - & & & & \\
\hline 3. Tempo de serviço & .079 & $-.158^{\star}$ & - & & & \\
\hline 4. Avaliação & -.014 & -.075 & -.010 & - & & \\
\hline 5. Cumprimento de objetivos & -.029 & .034 & -.097 & -.005 & - & \\
\hline 6. Prática científica e pedagógica & .049 & .007 & .040 & .082 & .115 & - \\
\hline 7. Perceção da Adequação do Processo de Avaliação & .015 & .013 & .047 & -.069 & -.095 & $-.373^{* *}$ \\
\hline
\end{tabular}




\section{DISCUSSÃO DE RESULTADOS E CONCLUSÕ E S}

Este estudo centrou-se na forma como os professores percecionam a ADD e a adequação (ou não) do processo. A pesquisa partiu de um modelo teórico que mapeava a $\mathrm{ADD}$ e a forma como esta prática é vista pelos professores. Face aos resultados encontrados, importa procurar sistematizar os seus contributos mais relevantes, refletindo sobre eles, na procura de um sentido integrador e coerente, assim como elencar um conjunto de pistas que conduzam a novos esforços de pesquisa.

Desta forma, é possível constatar, partindo dos resultados deste estudo, que o corpo docente feminino tem uma perceção mais negativa do processo avaliativo, relativamente ao género oposto. Contudo, a dimensão que mais valoriza é a que se refere ao Relatório de Autoavaliação (RAA) como uma fonte válida de avaliação de desempenho docente e que permite aos professores identificar os seus pontos fracos. O género masculino valoriza mais o facto de o RAA permitir identificar os seus pontos fracos e ser um instrumento de controlo da atividade docente. $\mathrm{O}$ aspeto menos valorizado pelo género masculino reporta à possibilidade do RAA identificar os pontos fortes da prática pedagógica.

Embora o relatório de autoavaliação possa constituir uma oportunidade de reflexão crítica e de consciencialização do professor acerca dos pontos fortes e das debilidades do seu desempenho nas suas funções (Alves, 2016; Cassettari, 2014), é de realçar que os inquiridos não valorizam o mesmo como um instrumento que lhes possibilite uma reflexão crítica relativamente às práticas implementadas. Tendo em consideração que qualquer processo de avaliação implica uma reflexão valorativa direcionada para uma prática futura (Alves, 2016; Cassettari, 2014), tal pode considerar-se um ponto fraco dos RAA, dado que, na opinião dos inquiridos, não cumprem esta função.

Relacionando o género com o cumprimento de objetivos, observa-se que os aspetos que são mais valorizados, em ambos os géneros, referem-se à apresentação de soluções para a melhoria do trabalho na escola e da frequência de ações de formação, de forma a contribuir para a melhoria das práticas pedagógicas. $\mathrm{O}$ aspeto que é menos relevante para o género feminino é o que diz respeito a manter o comportamento respeitoso e profissional no relacionamento com a direção, encarregados de educação, assistentes operacionais/administrativos e alunos, enquanto para o género masculino é a assiduidade.

Quanto à relação existente entre as variáveis género e prática científica e pedagógica, regista-se uma igualdade de opiniões nos itens mais valorizados, nomeadamente quando os professores referem que promovem de forma ativa a reflexão alargada, no âmbito das estruturas de coordenação educativa em que participam, sobre o desenvolvimento de ações/intervenções inovadoras, tendo em vista a eficácia e eficiência dos serviços prestados pela escola. Apresentam, ainda, sugestões com vista à melhoria da qualidade da escola no sentido de promover o trabalho colaborativo, de forma sistemática, em prol da consecução dos objetivos e metas dos referentes internos da escola. O mesmo acontece nos itens menos valorados, ou seja, quando avaliam sistematicamente as aprendizagens dos alunos com rigor, implementando práticas de avaliação diagnóstica, formativa e sumativa, e potencializando a interiorização, pelos alunos, das suas dificuldades e progressos.

No que diz respeito à relação entre as habilitações académicas e a perceção do processo avaliativo, observa-se que são coincidentes os itens com melhor score em todos os níveis de habilitação, nomeadamente o que refere que o RAA é uma fonte válida de avaliação de desempenho docente e que o mesmo serve para identificar os seus pontos fracos. Porém, o aspeto 
menos considerado pelos professores com mais habilitações aponta que o RAA não serve para nada, enquanto os que detêm menos habilitações entendem que o RAA reconhece os seus pontos fortes.

Quando são relacionadas as habilitações académicas com o cumprimento dos objetivos, independentemente do nível académico, os professores elegem os mesmos itens. Os mais valorizados reportam que os professores apresentam soluções para melhoria do trabalho na escola/ agrupamento e para a frequência de ações de formação, contribuindo para melhores práticas na escola.

Igualmente, ao serem comparadas as variáveis habilitações académicas e prática científica e pedagógica, verificam-se valores coincidentes nos diferentes níveis de habilitações. Os itens com valores mais elevados referem que os professores promovem de forma ativa a reflexão alargada, no âmbito das estruturas de coordenação educativa em que participam, sobre desenvolvimento de ações/intervenções inovadoras, tendo em vista a eficácia e eficiência dos serviços prestados pela escola. Também apresentam sugestões com vista à melhoria da qualidade da escola, no sentido de promover o trabalho colaborativo, de forma sistemática, em prol da consecução dos objetivos e metas dos referentes internos da escola. A questão menos valorizada é a que faz referência à avaliação sistemática das aprendizagens dos alunos com rigor, implementando práticas de avaliação diagnóstica, formativa e sumativa, potencializando a interiorização, pelos alunos, das suas dificuldades e progressos.

Observando as relações existentes entre o tempo de serviço dos professores e a perceção que os mesmos têm do processo de avaliação, verifica-se que os respondentes com mais tempo de serviço atribuem mais valor ao facto de o RAA permitir que os professores identifiquem oportunidades de desenvolvimento profissional e constituir uma fonte válida de avaliação de desempenho docente, enquanto os que apresentam menor tempo de serviço referem que o RAA é um instrumento de controlo da atividade docente e, igualmente, representa uma causa válida de avaliação de desempenho docente. Independentemente do tempo de serviço, o aspeto menos valorizado é que no RAA os professores identificam os seus pontos fortes.

Relacionando o tempo de serviço com o cumprimento dos objetivos, as opiniões dos professores são idênticas; os professores valorizam a apresentação de soluções para a melhoria do trabalho na escola/agrupamento e referem a importância da frequência de ações de formação, que contribuem para melhores práticas na escola. O item com pior score referese à questão da assiduidade. Os professores com mais tempo de serviço desvalorizam a questão da assiduidade, enquanto os que têm menos anos de profissão docente dão menos valor à questão da necessidade de se manter o comportamento respeitoso e profissional no trato com a direção, encarregados de educação, assistentes operacionais/administrativos e alunos.

Embora se denote carga fatorial baixa de alguns dos itens, tal não significa que o modelo proposto se apresente inadequado para descrever as relações entre as variáveis em estudo, mas antes incompleto para descrever a complexidade do processo de avaliação do desempenho docente. Os dados sugerem a necessidade de, em futuras investigações, incluirmos no modelo algumas variáveisque poderãoincrementar a compreensão do processo de avaliação docente e, logicamente, a variância explicada do modelo. Variáveis como a perceção de autoeficácia docente, abordagens ao ensino utilizadas em sala de aula, perceção dos processos autorregulatórios do professor, perceção dos processos de aprendizagem dos alunos, bem como a inteligência emocional revelada pelo professor, poderiam ser algumas das dimensões importantes que contribuiriam para uma visão mais holística desta área tão 
importante de estudo.

Não obstante os valores encontrados, estes resultados per se têm a mais-valia de revelar orientações e tendências acerca de um assunto ainda pouco estudado, bem como de poder apresentar dados em ADD resultantes de uma metodologia inovadora como foi a utilizada neste estudo, através de modelos de equações estruturais que nos permitem calcular, simultaneamente, todas as relações entre os fatores associados a um determinado fenómeno.

Outro aspeto a observar na relação encontrada no modelo para as variáveis endógenas em questão, relativamente à avaliação de desempenho e à perceção da adequação do processo de avaliação, pode ser explicado pelo facto de os professores já terem experienciado, negativamente, alguns modelos de avaliação impostos pela tutela, sem que os resultados dos mesmos tenham sido convenientemente avaliados. Consideramos que a fonte mais influente nas crenças da eficácia de qualquer tipo de avaliação docente provém da interpretação que os professores possam fazer sobre os resultados das suas realizações intencionais, aqui entendida como o cumprimento dos seus objetivos, assim como da consequente aplicabilidade na sua praxis docente. Neste sentido, uma perceção frágil da adequação de um processo de avaliação enfraquece a confiança do docente acerca desse processo avaliativo, desmotivando-o para a interiorização do mesmo e levando-o a evitar comprometer-se de uma forma empenhada.

Os resultados do estudo apresentam algumas limitações. Um aspeto prende-se com o tipo de amostra; investigações futuras devem contemplar amostras diferenciadas, incluindo variáveis como culturas diversificadas de inserção, satisfação na profissão docente, assim como incluir outros aspetos, como o clima das escolas e as relações interpessoais.

Refletir a ADD passa pela análise do processo de ensino e de aprendizagem, pelas relações entre alunos, professores, escola, órgãos decisores das políticas educativas e sociedade. A avaliação só faz sentido se as escolas e os professores se envolverem verdadeiramente no processo, em analisar e avaliar o trabalho realizado, aceitando, assim, todas as etapas do processo e os padrões de desempenho. Se os professores sentirem que exercem um controlo efetivo sobre o processo de avaliação, podem estar criadas oportunidades para uma melhoria do desempenho e das competências. De facto, ao sentirem que têm controlo sobre o processo, os professores tenderão a considerar que melhorar faz parte das suas responsabilidades enquanto profissionais de ensino (Fernandes, 2008).

O processo avaliativo docente é muito complexo, sendo, talvez, essa a razão que o torna aliciante e motiva o seu estudo mais aprofundado. Quando aceitamos a complexidade, tornase relativamente fácil compreender a situação concreta, de forma a criar uma organização harmoniosa e lógica das variáveis envolvidas. Quando somos capazes de compreender a importância de qualquer processo de avaliação do desempenho docente tendo como objetivo a mestria da sua praxis pedagógica, o processo de mudança está iniciado e é irreversível.

A complexidade do constructo que denominamos de Avaliação de Desempenho Docente faz com que o mesmo seja um conceito muito difícil de ser medido. Avaliar os seus componentes individuais não faz justiça ao seu caráter holístico, pois estamos conscientes de que nenhuma das dimensões da ADD, consideradas neste trabalho de investigação, é capaz de per se refletir a complexidade e diversidade dos esforços realizados pelos professores na explicação ou entendimento acerca da adequação (ou não) do processo de avaliação docente. 


\section{REFERÊ NCIAS}

Àlvarez, C. S. (2007). Práticas de avaliação de professores - Perspectiva espanhola. In C. C. Ramos (Dir.), Avaliação de professores - Visões e realidades. Actas da Conferência Internacional (pp. 60-67). Lisboa: Ministério da Educação - Conselho Cientifico para a Avaliação de Professores.

Alves, M. P. (2016). Avaliação de desempenho - Uma ferramenta de gestão. Lisboa: Escolar Editora.

Beatty, I. (2016). Oklahoma teachers' perceptions of the qualitative portion of the teacher evaluation system (Doctoral dissertation). University of Oklahoma, Oklahoma.

Bentler, P. M. (1990). Comparative fit indexes in structural models. Psychological Bulletin, 107, 238-246.

Bollen, K. A. (1989). A new incremental fit index for general structural equation models. Sociological Methods and Research, 17, 303-316.

Braz, A. B. (2013). A avaliação do desempenho docente enquanto estratégia promotora do desenvolvimento profissional dos professores (Tese de doutoramento). Instituto de Educação da Universidade de Lisboa, Lisboa.

Browne, M. W., \& Cudeck, R. (1993). Alternative ways of assessing model fit. In K. A. Bollen \& J. S. Long (Eds.), Testing structural equation models (pp. 445-455). Newbury Park, CA: Sage.

Bullis, B. B. (2014). The perceived impact of teacher performance ratings on the teacher evaluation process: Voices from the field (Doctoral dissertation). Loyola University Chicago, Chicago.

Byrne, B. M. (2001). Structural equation modelling with AMOS - Basic concepts, applications, and programming. New Jersey: Lawrence Erlbaum.

Cassettari, N. (2014). Avaliação de professores: Uma questão de escolhas. Estudos em Avaliação Educacional, 25(57),166-197.

Coelho, M. (2013). Avaliação de desempenho docente: Efeitos no desenvolvimento (Dissertação de Mestrado não publicada). Escola Superior de Educação, Instituto Politécnico de Lisboa, Lisboa.

Comissão Europeia/EACEA/Eurydice. (2013). Números-chave sobre os professores e os dirigentes escolares na Europa. Relatório Eurydice.
Luxemburgo: Serviço de Publicações da União Europeia.

Costa, L., \& Fialho, I. (2012). Avaliação do desempenho docente - Perceção dos professores sobre o último modelo de ADA e os seus efeitos nas práticas docentes (Um estudo de caso). In O. Magalhães \& A. Folque (Orgs.), I Jornadas de Investigação em Educação (pp. 195-216). Évora: Departamento de Pedagogia e Educação, Universidade de Évora.

Danielson, C. (2001). New trends in teacher evaluation. Educational Leadership, 58(5), 12-15.

Fernandes, D. (2008). A avaliação do desempenho docente: Desafios, problemas e oportunidades. Lisboa: Texto Editores.

Ferreira, C. A., \& Oliveira, C. (2015). Auto-avaliação docente e melhoria das práticas pedagógicas: Perceções de professores portugueses. Estudos em Avaliação Educacional, 26(63), 806-836.

Finney S. J., \& DiStefano C. (2006). Non-normal and categorical data in structural equation modeling. In G. R. Hancock \& R. O. Mueller (Eds.), Structural equation modeling. A second course (pp. 269-314). Greenwich, CT: Information Age Publishing.

Graça, A., Duarte, A., Lagartixa, C., \& Tching, D. (2011). Avaliação do desempenho docente: Um guia para a ação. Lisboa: Lisboa Editora.

Hadji, C. (2010). A avaliação de professores em França. Da inspeção ao acompanhamento? In M. A. Flores (Org.), A avaliação de professores numa perspectiva internacional - Sentidos e implicações (pp. 111-139). Maia: Areal.

Hair, J., Anderson, R., Tatham, R., \& Black, W. (2005). Análise multivariada de dados. Porto Alegre: Bookman.

Hu, L.-T., \& Bentler, P. M. (1995). Evaluating model fit. In R. H. Hoyle (Ed.), Structural equation modelling: Concepts, issues, and applications (pp. 76-99). Thousand Oaks, CA: Sage.

Isoré, M. (2010). Evaluación docente: Prácticas vigentes en los países de la OCDE y una revisión de la literatura. Santiago: PREAL.

Jöreskog, K. G., \& Sörbom, D. (1983). LISREL - 6 User's reference guide. Mooresville, IN: Scientific Software. 
Lima, J. (2008). Análise comparativa dos sistemas de avaliação do desempenho docente a nível europeu. Ozarfaxinars, 3. Disponível em: http://www. cfaematosinhos.eu/Analise\%20Comparativa $\% 20$ ADD.pdf

Lowe, B., Winzar, H., \& Ward, S. (2007). Essentials of SPSS for Windows versions 14 \& 15: A business approach. South Melbourne, Victoria: Thomson Learning Australia.

Machado, A. R, \& Portugal, M. N. (2014). Dicionário de recursos humanos. Lisboa: Clássica Editora.

Morgado, J. (2014). Avaliação e qualidade do desenvolvimento profissional docente: Que relação. Avaliação, 19(2), 345-361.

Murillo, F. J. (2007). Uma visão panorâmica da avaliação do desempenho docente na Europa e na América. In. C. C. Ramos (Coord.), Avaliação de professores - Visões e realidades, Atas da Conferência Internacional (pp. 33-54). Lisboa: Ministério da Educação, Conselho Científico para a Avaliação de Professores.

Pires, A. F. (2014). Avaliação de desempenho e desenvolvimento profissional do pessoal docente do ensino não superior: Dos normativos às práticas vigentes nas escolas de São Vicente, Cabo Verde (Tese de mestrado). Universidade Lusófona do Porto, Porto.

Raymond, M., \& Negassi, Y. (2015). O quinto compromisso. Desenvolvimento de um sistema de garantia do desempenho educativo em Portugal. Lisboa: Fundação Francisco Manuel dos Santos.

Rodrigues, S. (2012). Políticas de avaliação docente: Tendências e estratégias. Ensaio: Avaliação e Políticas Públicas em Educação, 20(77), 749-768.

Schmid, G. (2007). A perspetiva austríaca. In C. C. Ramos (Dir.), Avaliação de professores - Visões e realidades, Atas da Conferência Internacional (pp. 33-54). Lisboa: Ministério da Educação, Conselho Científico para a Avaliação de Professores.

Schreiber, J. B., Nora, A., Stage, F. K., Barlow, E. A., \& King, J. (2006). Reporting structural equation modeling and confirmatory factor analysis results: A review. The Journal of Educational Research, 99(6), 323-337.
Serrano, N. (2015). Perceção dos professores face à avaliação e face ao modelo de avaliação do desempenho docente (Dissertação de mestrado não publicada). Escola Superior de Educação, Instituto Politécnico de Castelo Branco, Castelo Branco.

Streiner, D. L. (2003). Being inconsistent about consistency: When coefficient alpha does and doesn't matter. Journal of Personality Assessment, 80, 217-222.

Ullman, J., \& Bentler, P. (2004). Structural equation modeling. In M. Hardy \& A. Bryman (Eds.), Handbook of data analysis (pp. 431-458). London: SAGE.

Urriola, K. M. (2013). Sistema de evaluación del desempeño profesional docente aplicado en Chile. Percepciones y vivencias de los implicados en el proceso (Tese de doutoramento). Universidade de Barcelona, Barcelona.

Ventura, A. (2012). Avaliação do desempenho dos professores como processo de desenvolvimento pessoal e profissional. Aprendizagem: A revista da prática pedagógica, 5(30), 56-57.

West, S. G., Finch, J. F., \& Curran, P. J. (1995). Structural equation models with non-normal variables: Problems and remedies. In R. Hoyle (Ed.), Structural equation modeling: Concepts, issues and applications (pp. 56-75). Newbury Park: Sage.

\section{LEG IS L AÇ Ã O CONSULTADA}

Décret n. ${ }^{\circ} 2002-682$, du 29 avril.

Decreto Regulamentar n. ${ }^{\circ}$ 2/2008, de 10 de janeiro.

Decreto Regulamentar n. ${ }^{\circ}$ 26/2012, de 21 de fevereiro.

Decreto-Lei n. ${ }^{\circ} 139$-A/90, de 28 de abril.

Decreto-Lei n. ${ }^{\circ}$ 15/2007, de 19 de janeiro.

Lei n. ${ }^{\circ} 46 / 86$, de 14 de outubro.

Parlamento Europeu (2014). Proposta de resolução, 2014-2019. B8-0235/2014 


\section{TEACHERS PERCEPTIONS ABOUT} TEACHER PERFORMANCE ASSESSMENT

\section{Abstract}

There is a consensus about the idea that the development of a country depends on the quality of its education. The Teaching Performance Assessment arises because the Ministry of Education believes that it can contribute to the quality of education, as well as to the personal and professional development of the teachers. However, the issue is complex and it gave origin to intense teaching and union's contestation in Portugal. This research aimed to know how teachers perceive teaching performance assessment. We carried out a quantitative research study with a sample of 240 teachers, to whom we applied a questionnaire. The data were treated and analyzed using the structural equation modeling technique. The main conclusions point to, concerning gender, academic abilities and time of service, the existence of some associations with the perception that teachers have about the adequacy of the performance assessment. Results reveal that the teachers who present a better understanding about the performance evaluation consider to better attain its objectives; they also demonstrate a better scientific and pedagogical practice, and show less appreciation of the adequacy of the teacher evaluation process.

KEY-WORDs: Assessment; Performance; Teachers

\section{PERCEPCIÓN DE LOS PROFESORES SOBRE LA EVALUACIÓN DEL DESEMPEÑO DOCENTE}

\section{RESUMEN}

Hay un consenso de que el desarrollo de un país depende de la calidad de su educación. La evaluación del desempeño docente surge debido a que el Ministerio de Educación cree que puede contribuir a la calidad de la educación, así como para la valorización y desarrollo personal y profesional de los profesores. Todavía, el tema es complejo y ha dado origen a intensa contestación docente e sindical en Portugal. Esta investigación ha pretendido conocer cómo los profesores percepcionan la evaluación del desempeño docente. Así, se ha llevado a cabo una investigación cuantitativa con una muestra de 240 profesores, a los cuáles se administró un cuestionario. Los datos recogidos han sido tratados y analizados recorriendo a la técnica de modelado de ecuaciones estructurales. Las principales conclusiones apuntan para, cuánto al género, habilitaciones académicas y tiempo de servicio, la existencia de algunas asociaciones con la percepción que os profesores poseen sobre la adecuación de la evaluación del desempeño. Los resultados revelan que los profesores que presentan una mejor comprensión de la evaluación de desempeño, consideran cumplir más los objetivos y tienen una mejor práctica científica y pedagógica; de manifiesto, son los que también muestran menor percepción de la adecuación del proceso de evaluación docente.

Palabras-Clave: Evaluación; Desempeño; Profesores

\footnotetext{
${ }^{\mathrm{I}}$ Departamento de Ciência Política e do Comportamento, Faculdade de Ciências Humanas e Sociais, Universidade Fernando Pessoa, Portugal. ORCID: 0000-0001-8631-7815

"Departamento de Ciência Política e do Comportamento, Faculdade de Ciências Humanas e Sociais, Universidade Fernando Pessoa, Portugal. ORCID: 0000-0003-3219-4543

${ }^{\text {II }}$ Centro de Investigação em Psicologia e Educação (CIPE), Agrupamento de Escolas Alexandre Herculano, Portugal. ORCID: 0000-0001-69200412

rv Departamento de Educação e Psicologia, Escola de Ciências Humanas e Sociais, Universidade de Trás-os-Montes e Alto Douro, Portugal. ORCID: 0000-0002-4082-1474
} 